\title{
Self-care behavior of type 2 diabetes mellitus patients in Bandar Abbas in 2015
}

\author{
Fatemeh Karimi ${ }^{1}$, Sedigheh Abedini ${ }^{2}$, Shokrollah Mohseni ${ }^{3}$
}

\author{
${ }^{1}$ M.Sc. Student of Health Education, Health School, Hormozgan University of Medical Sciences, Bandar Abbas, \\ Iran \\ ${ }^{2}$ Assistant Professor of Health Education, Social Determinants on Health Promotion Research Center, Faculty of \\ Health, Hormozgan University of Medical Sciences, Bandar Abbas, Iran \\ ${ }^{3}$ Instructor in Statistics, Social Determinants on Health Promotion Research Center, Hormozgan University of \\ Medical Sciences, Bandar Abbas, Iran
}

\section{Type of article: Original}

\begin{abstract}
Background: Diabetes self-care helps to control the blood sugar which, in turn, results in a better state of health. However, more than $50 \%$ of diabetic patients do not have self-care capabilities.

Objective: To determine type 2 diabetes self-care capabilities among patients visiting a Bandar Abbas diabetes clinic in 2016.

Methods: The present descriptive-analytical research was of a cross-sectional type. The sample was comprised of 120 patients afflicted with type 2 diabetes, who had been selected through the simple randomized sampling method. The data collection instrument was a questionnaire comprised of two sections: demographic information, and a summary of patients' diabetes self-care activities. A 7-point Likert scale was used for the rating. The final score would be interpreted as any of the three levels: good (acceptable) (75-100), moderate (50-74) and poor (below 50). The data entered SPSS version 18.0 for the required statistical analyses.

Results: The mean age of the sample was $51.88 \pm 10.12$ years. Of the 120 subjects, 86 were female $(71.7 \%)$ and 34 were male $(28.3 \%)$. The findings revealed that the self-care capability of 83 subjects $(69.2 \%)$ was poor; capability of 28 subjects was moderate (23.3\%) and the same score of good/acceptable in 9 subjects $(7.5 \%)$.

Conclusion: The results of the present research indicate that a large number of diabetic patients have a poor selfcare capability. Due to the key role of such activities in a diabetic patient's life, it is suggested to include educational programs to increase the level of self-care capabilities among these patients.
\end{abstract}

Keywords: Self-care behaviors, Type 2 diabetes mellitus, Glucometer

\section{Introduction}

\subsection{Background}

As the most prevalent and significant metabolic disease, type 2 diabetes is considered as a key healthcare problem throughout the world. About $90-95 \%$ of diabetic patients are afflicted with type 2 diabetes, which emerges at the age above 40. Huge costs are annually imposed on healthcare systems (1). This disease is marked by a high pathogenesis, both in terms of the treatments and disability involved, and this makes it a main human medical and healthcare problem. Mortality induced by diabetes, ranks fifth in the world (2). According to WHO statistics, the growing population could make the prevalence of diabetes' rise from $4 \%$ in 1995 to $5.4 \%$ in 2025 (3). The total number of patients afflicted with diabetes is expected to reach 6 million victims in 2030 (4). The prevalence of overt diabetes in Hormozgan Province was reported to be $0.8 \%$ (5).

\section{Corresponding author:}

Assistant Professor Dr. Sedigheh Abedini, Social Determinants on Health Promotion Research Center, Faculty of Health, Hormozgan University of Medical Sciences, Bandar Abbas, Iran.

Tel: +98.7633338788, Email: sabedini45@yahoo.com

Received: December 01, 2016, Accepted: January 25, 2017, Published: November 2017

iThenticate screening: January 24, 2017, English editing: February 09, 2017, Quality control: August 27, 2017

This article has been reviewed / commented by three experts

(C) 2017 The Authors. This is an open access article under the terms of the Creative Commons Attribution-NonCommercialNoDerivs License, which permits use and distribution in any medium, provided the original work is properly cited, the use is non-commercial and no modifications or adaptations are made. 


\subsection{Statement of problem}

More than $95 \%$ of the treatment in type 2 diabetes is carried out by the patients themselves. The medical team has less control on patients between the visits (6). This disease requires specific life-long self-care behavior. Self-care is an active and practical process guided by the patient, and aims for improved physical conditions or maintaining healthcare through such actions as a diet, physical exercise, monitoring blood sugar and searching for preventive healthcare or therapeutic services and applying the prescribed therapies to such diseases and disorders as diabetes. The majority of research indicates that diabetes self-care helps to control patients' blood sugar which in turn leads to better healthcare results (7). Although the patients' knowledge on self-care is inadequate (8), diabetes self-care has significantly cut down on the rate of hospitalization and prevented the acute and chronic side effects of the disease or delayed the consequences.. It also helps to improve the quality of life and lower the costs. The importance of selfcare for management of diabetes mellitus is reported by several researchers $(9,10)$. Also, some authors have reported successful interventions to improve self-care and diabetes management (11-13). High rate of mortality and the consequences of diabetes, high costs and the resultant individual and social loads highlight the immediate need for helping diabetic patients for a better control of patients. Therefore, an investigation of patients' self-care ability can contribute to self-care programs.

\subsection{Objective}

The present research aimed to determine the self-care ability of type 2 diabetic patients who visited the Diabetes Clinic of Bandar Abbas in 2016.

\section{Material and Methods}

\subsection{Study design and setting}

In the present descriptive-analytic research which was of a cross-sectional type, diabetic patients' self-care ability was investigated. For sample size calculation, the self-care score was considered as $32.7 \pm 12.6$ based on a study in Khorramabad (14). A total of 120 samples were included using convenience sampling method from all type 2 diabetic patients who visited in the Diabetes Clinic of Bandar Abbas in February and March, 2015.

\subsection{Inclusion and exclusion criteria}

The inclusion criteria were: having an active medical file, being literate, over one year of affliction with the disease, having no serious side effect such as diabetic foot injuries, and not being pregnant (in the case of female participants). The exclusion criteria were: advanced stages of the disease such as advanced kidney failure, brain stroke, heart attack, malignant tumor, diabetic foot injury, history of psychotherapy (due to a lack of self-care ability) and patient's reluctance to take part in the research.

\subsection{Data collection}

The instrumentation was a questionnaire designed by Toobert et al (15) in 2000, comprised of two sections, the first of which had 18 items investigating patient's demographic information, educational background, history, and treating patients independently from their self-care ability. The patients were divided into 3 groups based on their income including low income (less than 10 million Rials), middle income (10-20 million Rials), and high income (more than 20 million Rials). The second section was concerned with patient's self-care ability comprised of 10 items. A 7-point scale was used for the rating. In this Likert scale, each and every item was to be rated from 0 to 7 . If the patient followed all the self-care procedures throughout the whole week, s/he would rate 7 and if otherwise, s/he did not follow them, then would rate 0 . The overall score would be out of 100 , and the self-care ability was divided into three levels: acceptable (75-100), moderate $(50-74$ and poor $(<50)$, based on the questionnaire instruction. For data collection interview method was used.

\subsection{Ethics}

Having gone through the authorization procedures and followed ethical issues such as the confidentiality of data, participants' full consent and willingness to take part in the study, and revealing the purpose of research, the researcher submitted the questionnaires to all subjects, and later collected them.

\subsection{Statistics}

The collected data were later analyzed, using SPSS version 18.0 following descriptive statistics (frequency, relative frequency, mean and standard deviation) as well as analytical tests such as t-test and one-way ANOVA. 


\section{Results}

\subsection{Demographics}

The mean age of the subjects was $51.88 \pm 10.129$ years and the duration of affliction with diabetes was $6.988 \pm 10.39$. According to the findings, in terms of the gender of the participants, 86 subjects $(71.7 \%)$ were female and 34 subjects $(28.3 \%)$ were male. In terms of education, 96 subjects $(80 \%)$ were literate. Concerning marital status, 101 subjects $(84.2 \%)$ were married while 19 subjects $(15.8 \%)$ were single. As for occupation, 76 subjects $(63.3 \%)$ were housewives. 114 of the participants (95\%) were insured. Eight subjects $(6.7 \%)$ had a history of smoking. Of those subjects who monitored their blood sugar as advised by the doctor, there were 85 (70.8\%). Furthermore, 68 subjects $(56.7 \%)$ had a concomitant chronic disease. In terms of a history of hospitalization due to diabetes, 36 subjects (30\%) had already been hospitalized 1-2 times; of these, 12 subjects (10\%) had been hospitalized more than 2 times. Among the participants, $49(40.8 \%)$ had the experience of attending diabetes education courses.

\subsection{Study main results}

The findings related to self-care ability, revealed that 83 subjects $(69.2 \%)$ had a poor ability; 28 subjects (23.3\%) had a moderate ability and 9 subjects $(7.5 \%)$ had an acceptable self-care ability. The score for self-care behavior was not statistically significantly different according to demographic variables. Details are shown in Table 1.

Table 1. Mean and standard deviation of self-care behavior score based on demographic variables

\begin{tabular}{|c|c|c|c|c|c|}
\hline \multicolumn{2}{|l|}{ Factor } & Number (percent) & Mean & Standard deviation & $\mathrm{p}$-value \\
\hline \multirow[t]{2}{*}{ Sex } & Male & $34(28.3)$ & 27.55 & 12.22 & \multirow[t]{2}{*}{0.198} \\
\hline & Female & $86(71.7)$ & 31.25 & 14.77 & \\
\hline \multirow[t]{3}{*}{ Age group (year) } & $25-40$ & $19(15.8)$ & 27.89 & 14.80 & \multirow[t]{3}{*}{0.122} \\
\hline & $41-55$ & $56(46.7)$ & 28.25 & 12.48 & \\
\hline & $56-74$ & $45(37.5)$ & 33.62 & 15.42 & \\
\hline \multirow[t]{5}{*}{ Education } & Uneducated & $24(20)$ & 28.95 & 16.9 & \multirow[t]{5}{*}{0.53} \\
\hline & Primary school & $27(22.5)$ & 34.03 & 14.71 & \\
\hline & Junior high school & $35(29.2)$ & 30.34 & 13.24 & \\
\hline & Diploma & $23(19.2)$ & 28.74 & 12.77 & \\
\hline & Collegiate & $11(9.2)$ & 26.72 & 11.82 & \\
\hline \multirow[t]{3}{*}{ Income } & Low income & $78(65)$ & 30.12 & 15.05 & \multirow[t]{3}{*}{0.969} \\
\hline & Middle income & $38(31.7)$ & 30.52 & 12.67 & \\
\hline & High income & $4(3.3)$ & 28.75 & 11.64 & \\
\hline \multirow[t]{2}{*}{ Marital status } & Married & $101(84.2)$ & 29.54 & 13.93 & \multirow[t]{2}{*}{0.238} \\
\hline & Single & $19(15.8)$ & 33.73 & 15.13 & \\
\hline \multirow[t]{4}{*}{ Occupation } & Housewife & $76(63.3)$ & 30.73 & 14.93 & \multirow[t]{4}{*}{0.655} \\
\hline & Employed & $12(10)$ & 25.25 & 10.96 & \\
\hline & Retired & $16(13.3)$ & 30.93 & 13.10 & \\
\hline & Unemployed/Free & $16(13.3)$ & 30.68 & 13.81 & \\
\hline \multirow{4}{*}{ Disease period (year) } & $1-4$ & $28(23.3)$ & 25.78 & 14.98 & \multirow[t]{4}{*}{0.257} \\
\hline & $5-10$ & $42(35)$ & 31.28 & 14.13 & \\
\hline & $11-15$ & $29(24.2)$ & 32.93 & 13.41 & \\
\hline & $16-40$ & $21(17.5)$ & 30.19 & 13.62 & \\
\hline \multirow[t]{2}{*}{ Educational background } & Have & $71(59.2)$ & 30.71 & 13.97 & \multirow[t]{2}{*}{0.637} \\
\hline & Have not & $49(40.8)$ & 29.46 & 14.51 & \\
\hline
\end{tabular}

\section{Discussion}

The present research aimed to investigate type 2 diabetic patients' self-care ability, who visited the Diabetes Clinic of Bandar Abbas. The findings revealed that $83(69.2 \%)$ of the total 120 subjects had a poor self-care ability. This finding is consistent with the results reported by Vosoughi Karkarlou et al. (16). However, these were not similar to the results obtained by Baghaee et al. in Kashan and also Parham et al. in Qom, which reported a moderate level of patients' self-care ability $(17,18)$. The reason for this divergence could be due to the different education level as well as the dominant female gender among the subjects. In fact, in the present study, 86 subjects $(71.7 \%)$ of the total 120 subjects were illiterate or semi-literate. In contrast, in the studies of Baghaee et al. and Parham et al., the percentage of illiterate and semi-literate subjects was low $(17,18)$. Moreover, in the present study, the majority of patients (71.7\%) were afflicted with diabetes. To the contrary, in Parham et al.'s study, only $51.6 \%$ of the 
participants were female (18). The highest percentage of diabetes in this study belonged to women. There is a great body of research which also attests to the increasing rate of type 2 diabetes among women (19). In the present research, the majority of participants had no academic degree. It can be concluded that low education could have kept their awareness and ability of self-care to the minimum. Badroddin also maintains that low literacy in developing countries accounts for patients' inadequate understanding of the disease and, therefore, disrupts self-care (20). Some people lack a reliance on assessing their own health. Adults aged between 25-60 years old often take the parents' role and are the breadwinners. Their health stands in the center of a whole family's or society's health. They usually manage their family members' healthcare, including their children or the elderly living with them. However, they attend less to their own state of health, and spend little time caring about themselves. With this regard, again it seems that one main reason for poor self-care behavior is patients' inadequate awareness and knowledge of the ways of self-care provision. Considering the significant role of education programs in promoting self-care behavior, selfcare programs need to be performed in regular and consistent sessions. We hope raising patients' awareness can help to increase diabetic patients' self-care ability and lower the risks of this disease. Another finding of this study was that women's mean self-care ability score was higher than men's. However, this divergence was not statistically significant, which is consistent with the findings reported by Artinian et al. (21). In Aboutalebi et al.'s research in Ardabil which investigated self-care ability among patients suffering from hypertension, men showed to have a higher ability than women. This finding is divergent to that of the present research. Gender seems to affect self-care ability, but itself is a function of such other variables as knowledge, physical state, mental state and behavioral state (22). As an example, Aboutalebi attributed men's higher self-care ability to their higher education as compared to women, in his study of hypertension. Considering the complicated nature of human beings, more in-depth investigation of self-care behavior, especially of chronic diseases such as diabetes, can provide useful information for better medical and therapeutic plans. The present research suffered from certain limitations. The target research population, was all patients who visited the Diabetes Clinic in Bandar Abbas. This could be non-representative of the state of all diabetic patients in this city.

\section{Conclusions}

In the present research, subjects' self-care ability was found to be poor. Since self-care behavior plays a key role in preventing preterm or post-term side effects of the disease as well as life expectancy, it is suggested that educational programs need to be run by medical and healthcare teams, so as to promote self-care ability among patients. It is recommended to increase self-care ability of patients with diabetes mellitus through educating self-care behavior. Studies on the effectiveness of educational programs on self-care behavior is recommended.

\section{Acknowledgments:}

The present paper has been part of an M.S. thesis of Health Education, whose project was approved and authorized by the Research Deputy of Hormozgan University of Medical Sciences. It had the benefit of financial support by the Research Deputy in the same university. The researcher should like to express gratitude to the esteemed authorities of the research center of Hormozgan University of Medical Sciences, the cooperative staff of Bandar Abbas Diabetes Clinic affiliated with Shahid Mohammadi Hospital. The researcher feels further indebted to all patients who participated in this research.

\section{Conflict of Interest:}

There is no conflict of interest to be declared.

\section{Authors' contributions:}

All authors contributed to this project and article equally. All authors read and approved the final manuscript.

\section{References:}

1) Barati M. Predicting Factors Related to Self-care Behaviors among Type 2 Diabetic Patients based on Health Belief Model. Journal of Torbat Heydariyeh University of Medical Sciences. 2014; 1(4): 16-25.

2) Morowatisharifabad M, Tonekaboni NR. Perceived self-efficacy in self-care behaviors among diabetic patients referring to Yazd Diabetes Research Center. Journal of Birjand University of Medical Sciences. 2008; 15(4): 91-9.

3) Jalilian F, Zinat Motlagh F, Solhi M. Effectiveness of Education Program on Increasing Self Management Among Patients with Type II Diabetes. Journal of Ilam University of Medical Sciences. 2012; 20(1): 26-34. 
4) Afshari M, Tol A, Taghdisi M, Azam K. The effect of the combinatorial program on improving foot care in type 2 diabetic patients referred to diabetes clinic of Samirom city: Application of BASNEF model. J Health Syst Res. 2014: 1697-707.

5) Aghamolaie M, Sobhani A, Yousefi HF. A. Behavior and metabolic control in diabetic patients in Bandar Abbas diabetic clinic (1382). Hormozgan Medical Journal. 2003; 7(3): 111-5.

6) Firooz M, Mazlom R, Hoseini J, Hasanzadeh F, Kimiae A. Comparison between the effect of group education and group counseling on emotional self-care in type II diabetics. Journal of Birjand University of Medical Sciences. 2015; 22(4): 293-303.

7) Didarloo A, Shojaeizadeh D, Eftekhar Ardebili H, Niknami S, Hajizadeh E, Alizadeh M. Assessment of factors affecting self-care behavior among women with type 2 diabetes in Khoy City Diabetes Clinic using the extended theory of reasoned action. Journal of School of Public Health and Institute of Public Health Research. 2011; 9(2): 79-92.

8) Tewahido D, Berhane Y. Self-Care Practices among Diabetes Patients in Addis Ababa: A Qualitative Study. PLoS One. 2017; 12(1): e0169062. doi: 10.1371/journal.pone.0169062. PMID: 28045992. PMCID: PMC5207399.

9) Koponen AM, Simonsen N, Suominen S. Determinants of physical activity among patients with type 2 diabetes: the role of perceived autonomy support, autonomous motivation and self-care competence. Psychol Health Med. 2017; 22(3): 332-44. doi: 10.1080/13548506.2016.1154179. PMID: 26952696.

10) Yee LM, McGuire JM, Taylor SM, Niznik CM, Simon MA. Factors promoting diabetes self-care among low-income, minority pregnant women. J Perinatol. 2016; 36(1): 13-8. doi: 10.1038/jp.2015.134. PMID: 26513455.

11) Cortez DN, Macedo MM, Souza DA, Dos Santos JC, Afonso GS, Reis IA, et al. Evaluating the effectiveness of an empowerment program for self-care in type 2 diabetes: a cluster randomized trial. BMC Public Health. 2017; 17(1): 41. doi: 10.1186/s12889-016-3937-5. PMID: 28061840, PMCID: PMC5219728.

12) Williams JS, Walker RJ, Smalls BL, Hill R, Egede LE. Patient-Centered Care, Glycemic Control, Diabetes Self-Care, and Quality of Life in Adults with Type 2 Diabetes. Diabetes Technol Ther. 2016; 18(10): 6449. doi: 10.1089/dia.2016.0079. PMID: 27541872, PMCID: PMC5069713.

13) Waki S, Shimizu Y, Uchiumi K, Asou K, Kuroda K, Murakado N, et al. Structural model of self-care agency in patients with diabetes: A path analysis of the Instrument of Diabetes Self-Care Agency and body self-awareness. Jpn J Nurs Sci. 2016; 13(4): 478-86. doi: 10.1111/jjns.12127. PMID: 27224894, PMCID: PMC5089640.

14) Anbari K, Ghanadi K, Kaviani M, Montazeri R. The self care and its related factors in diabetic patients of khorramabad city. scientific magazine yafte. 2012; 14(4): 49-57.

15) Toobert DJ, Hampson SE, Glasgow RE. The summary of diabetes self-care activities measure: results from 7 studies and a revised scale. Diabetes Care. 2000; 23(7): 943-50. PMID: 10895844.

16) Vosoghi Karkazloo N, Abootalebi Daryasari G, Farahani B, Mohammadnezhad E, Sajjadi A. The study of self-care agency in patients with diabetes (Ardabil). Modern Care Journal. 2012; 8(4): 197-204.

17) Baghaei P, Zandi M, Vares Z, Masoudi Alavi N, Adib-Hajbaghery M. Self care situation in diabetic patients referring to Kashan Diabetes Center, in 2005. Feyz Journal of Kashan University of Medical Sciences. 2008; 12(1): 88-93.

18) Parham M, Riahin A, Jandaghi M, Darivandpour A. Self Care Behaviors of Diabetic Patients in Qom. Qom Univ Med Sci J. 2012; 6(4): 81-7.

19) Bagheri H, Abrahimi H, Taghavi N, Hasani MR. Evaluation of quality of life of diabetic patients on diabetic complications referring to Imam Hossein Hospital of shahrod city. Journal of Shahroud University of Medical Sciences. 2005; 7(2): 50-60.

20) Badruddin N, Basit A, Hydrie MZI, Hakeem R. Knowledge, attitude and practices of patients visiting a diabetes care unit. Pakistan Journal of Nutrition. 2002; 1(2): 99-102. doi: 10.3923/pjn.2002.99.102.

21) Artinian NT, Magnan M, Sloan M, Lange MP. Self-care behaviors among patients with heart failure. Heart Lung. 2002; 31(3): 161-72. PMID: 12011807.

22) Abotalebi G. The study of self- care agency based on orems theory in individuals with hypertension admitted to the selected hospitals of Ardebil [dissertation].the thesis for the degree of M.S.C in medical surgical nursing, Tehran. Islamic azad university medical sciences branch. 2009. 